07

\title{
Особенности взаимодействия протонов с транзисторными структурами с двумерным AIGaN/GaN-каналом
}

\author{
(C) В.В. Емцев ${ }^{1}$, Е.Е. Заварин ${ }^{1}$, М.А. Козловский ${ }^{1}$, \\ М.Ф. Кудояров ${ }^{1}$, В.В. Лундин ${ }^{1}$, Г.А. Оганесян ${ }^{1}$, В.Н. Петров ${ }^{1}$, \\ Д.С. Полоскин ${ }^{1}$, А.В. Сахаров ${ }^{1}$, С.И. Трошков ${ }^{1}$, Н.М. Шмидт ${ }^{\uparrow}, 1$, \\ В.Н. Вьюгинов ${ }^{2}$, А.А. Зыбин ${ }^{2}$, Я.М. Парнес ${ }^{2}$, С.И. Видякин ${ }^{3}$, \\ А.Г. Гудков ${ }^{3}$, А.Е. Черняков ${ }^{4}$, В.В. Козловский ${ }^{5}$ \\ ${ }^{1}$ Физико-технический институт им. А.Ф. Иоффе РАН, Санкт-Петербург \\ ${ }^{2}$ ЗАО „Светлана-Электронприбор“, Санкт-Петербург \\ ${ }^{3}$ Московский государственный технический университет \\ им. Н.Э. Баумана, Москва \\ ${ }^{4}$ НТЦ микроэлектроники РАН, Санкт-Петербург \\ ${ }_{5}^{5}$ Санкт-Петербургский политехнический университет Петра Великого \\ ๑ E-mail: Natalia.Shmidt@mail.ioffe.ru
}

Поступило в Редакцию 30 марта 2016 г.

Показано, что взаимодействие протонов с энергией $1 \mathrm{MeV}$ и дозами $(0.5-2) \cdot 10^{14} \mathrm{~cm}^{-2}$ с транзисторными структурами с двумерным AlGaN/GaNканалом (AlGaN/GaN-HEMT) сопровождается не только генерацией точечных дефектов, но и образованием локальных областей с разупорядоченным наноматериалом. Степень разупорядоченности наноматериала оценивалась количественно методами мультифрактального анализа. Увеличение степени разупорядоченности наноматериала, наиболее ярко проявляющееся при дозе протонов $2 \cdot 10^{14} \mathrm{~cm}^{-2}$, приводит к падению подвижности и электронной плотности в двумерном канале НЕМТ-структур в несколько раз. При этом на транзисторах наблюдается падение величины тока сток-исток и рост тока утечки затвора на порядок. В НЕМТ-структурах с повышенной разупорядоченностью наноматериала до воздействия протонов, облучение протонами, даже с дозой $1 \cdot 10^{14} \mathrm{~cm}^{-2}$, приводит к подавлению двумерной проводимости в канале и выходу из строя транзисторов.

Транзисторы на основе AlGaN/GaN-наногетероструктур с высокой подвижностью электронов в двумерном канале (AlGaN/GaN-HEMT) являются частью элементной базы полупроводниковой СВЧ-электроники. 
При функционировании в космосе эти приборы подвергаются воздействию потоков частиц высоких энергий от 1 до $10^{12} \mathrm{GeV}$, приходящих из Галактики и от Солнца. Львиную долю в этом потоке, около 90\%, занимают протоны. В последнее десятилетие изучение влияния различных видов ионизирующих излучений на образование дефектов в полупроводниковых материалах, на работоспособность и надежность приборов, в том числе приборов СВЧ-электроники для космических применений, приобрело особую актуальность. Большое число работ посвящено этой тематике. Наибольшее внимание уделено изучению точечных радиационных дефектов, а в AlGaN/GaN-HEMT — выяснению физики явлений, приводящих к изменению основных параметров транзисторов. Существенно меньше изучена роль разупорядоченных областей, возникающих под действием ионизирующих излучений. Между тем в отдельных работах [1,2], выполненных на традиционных полупроводниках, отмечается, что такие области играют существенную роль в процессах рекомбинации неравновесных носителей. Кроме того, хорошо известно, что разная степень разупорядоченности наноматериала свойственна слоям [3] и приборным структурам [4] на основе нитридов третьей группы и без воздействия ионизирующих излучений. Разупорядоченность наноматериала вызвана спецификой роста этих материалов на зародышевых слоях, в неравновесных условиях с большими рассогласованиями (до 13\%) постоянных решетки подложки и слоев и формированием мозаичной (колончатой) структуры, сросшейся по дислокационным и дилатационным границам, пронизывающим всю структуру. Эти ростовые особенности приводят к сосуществованию микро- и нанообластей двумерного и трехмерного характера роста в одной структуре со слабой разориентацией относительно друг друга и, как следствие, к разупорядоченному рельефу поверхности, отражающему сложную внутреннюю организацию наноматериала $[3,4]$. Сложная внутренняя организация наноматериала приводит к случайным флуктуациям состава твердого раствора и к неоднородному распределению локальных механических напряжений. Система протяженных дефектов, пронизывающая НЕМТ-структуру, содержит прорастающие дислокации различного типа, в том числе дислокации с открытым ядром ( $V$-дефекты), скопления дислокаций, дислокационные стенки, а также дефекты упаковки с общей плотностью до $10^{8} \mathrm{~cm}^{-2}$. Свойства отдельных элементов этой системы существенно различаются по проводимости. Ранее было выяснено, что сложная внутренняя организация наноматериала, по существу фрактальная, заметно влияет на частотные

Письма в ЖТФ, 2016, том 42, вып. 21 
характеристики AlGaN/GaN-HEMT [5], а также на величину подвижности носителей заряда в слоях нитрида галлия [3].

Целью работы явилось изучение разупорядоченности наноматериала, возникающее при взаимодействии протонов с $\mathrm{AlGaN} / \mathrm{GaN}-\mathrm{HEMT}$ структурами, ее влияние на подвижность электронов в двумерном канале и на параметры транзисторов.

При решении поставленной задачи опирались на ранее разработанную и апробированную методику количественной оценки характера организации наноматериала с помощью мультифрактального параметра степени нарушения локальной симметрии (степень разупорядочения наноматериала $\Delta_{p}$ ) [3]. Методика основана на том, что в материалах со сложной внутренней структурой особенности морфологии отражают характер организации наноматериала. Благодаря этому обработка математического множества, соответствующего изображению поверхности слоя или структуры в атомно-силовом микроскопе, методами мультифрактального анализа по программе MFDROM [6] позволяет количественно охарактеризовать степень разупорядоченности $\left(\Delta_{p}\right)$. Точность определения параметра $\Delta_{p} \pm 0.002$. Увеличение значений параметра $\Delta_{p}$ по абсолютной величине коррелирует с усложнением морфологии поверхности структур (появление более развитого рельефа), вызванным ухудшением согласования блоков мозаичной структуры, увеличением протяженности дислокационных стенок и количества скоплений дислокаций с одновременным увеличением неоднородности их распределения, хотя увеличения общей плотности одиночных дислокаций при этом может не наблюдаться [3,7]. Эксперименты проводились на $\mathrm{AlGaN} / \mathrm{GaN}$-HEMT-структурах, выращенных методом MOCVD, конструктивные и технологические подробности приведены в [8]. Для исследований были выбраны два типа НЕМТ-структур, существенно отличающихся только по характеру организации наноматериала, со значениями $\Delta_{p} 0.345$ и 0.350 . Из структур каждого типа были сделаны образцы с омическими контактами для измерения подвижности электронов в двумерном канале НЕМТ-структур методом Ван-дер-Пау, а также транзисторы в ЗАО „Светлана-Электронприбор“ с топологией, приведенной в [8]. Облучение проводилось протонами, ускоренными на циклотроне ФТИ им. А.Ф. Иоффе до энергии $1.0 \mathrm{MeV}$, в вакууме $10^{-5}$ Torr. От типа образцов HEMT-структур и небольшие партии транзисторов из этих же структур облучались протонами с дозами $5 \cdot 10^{13}, 1 \cdot 10^{14}, 2 \cdot 10^{14} \mathrm{~cm}^{-3}$. Морфология поверх- 
ностей структур до и после облучения изучалась методом атомносиловой микроскопии (ACM), количественно оценивался общепринятый параметр оценки шероховатости поверхности RMS и максимальные отклонения величины шероховатости Peak-to-peak $(P p)$, а также значения $\Delta_{p}$.

Взаимодействие протонов с $\mathrm{AlGaN} / \mathrm{GaN}-\mathrm{HEMT-структурами} \mathrm{сопро-}$ вождается возникновением разупорядоченных локальных областей наноматериала, нарушением и уширением ростовых ступеней. Наиболее ярко эти изменения выражены после воздействия протонов с дозой $2 \cdot 10^{14} \mathrm{~cm}^{-2}$. На рис. 1 представлены АСМ-изображения поверхностей типичных участков НЕМТ-структуры с $\Delta_{p}=0.345$ до $(a)$ и после $(b)$ облучения протонами. Разупорядоченность наблюдается практически на всей поверхности НЕМТ-структуры, но ее характер отличается на разных участках. Количественные оценки параметра $\Delta_{p}$ на разных участках этой структуры дают значения от 0.350 до 0.365 , в то время как до облучения протонами разупорядоченность наноматериала и разброс значений $\Delta_{p}$ на разных участках были заметно меньше 0.345-0.348. Эти результаты коррелируют с данными по шероховатости поверхности. Значение параметра RMS в полях $2 \times 2 \mu \mathrm{m}$ на разных участках структуры $0.2320-0.3375 \mathrm{~nm}$ до облучения возрастает до значений $0.5115-0.8170 \mathrm{~nm}$ после облучения и отражает значительное увеличение разброса между участками одной и той же структуры. Параметр $P$, регистрирующий максимальную разницу по высоте рельефа в отдельных точках исследуемых участков, дает разброс $2.262-2.654 \mathrm{~nm}$ до воздействия и $8-25 \mathrm{~nm}$ после воздействия. Усиление разупорядоченности наноматериала НЕМТ-структуры сопровождается падением подвижности электронов в двумерном канале (рис. 2, кривая 2) относительно значений до облучения (рис. 2, кривая 1). Кроме того, на транзисторах наблюдается падение тока сток-исток на порядок и рост тока затвора, а часть транзисторов (до 40\%) перестает функционировать. При дозе $10^{14} \mathrm{~cm}^{-2}$ количество нефункционирующих транзисторов существенно уменьшилось до $20 \%$, а на остальных падение тока незначительное. При дозе $5 \cdot 10^{13} \mathrm{~cm}^{-2}$ никаких изменений не наблюдается. Полученные результаты на транзисторах с $\Delta_{p}=0.345$ соответствуют лучшим опубликованным [9]. На НЕМТ-структурах с повышенной разупорядоченностью $\left(\Delta_{p}=0.350\right)$ до облучения падение подвижности электронов в двумерном канале аналогично представленному на рис. 2, кривая 2, но наблюдается уже при дозе протонов $10^{14} \mathrm{~cm}^{-2}$. При этом разупорядоченность по всей структуре $\Delta_{p}=0.365$ (рис. $1, c$ ). Кроме

Письма в ЖТФ, 2016, том 42, вып. 21 

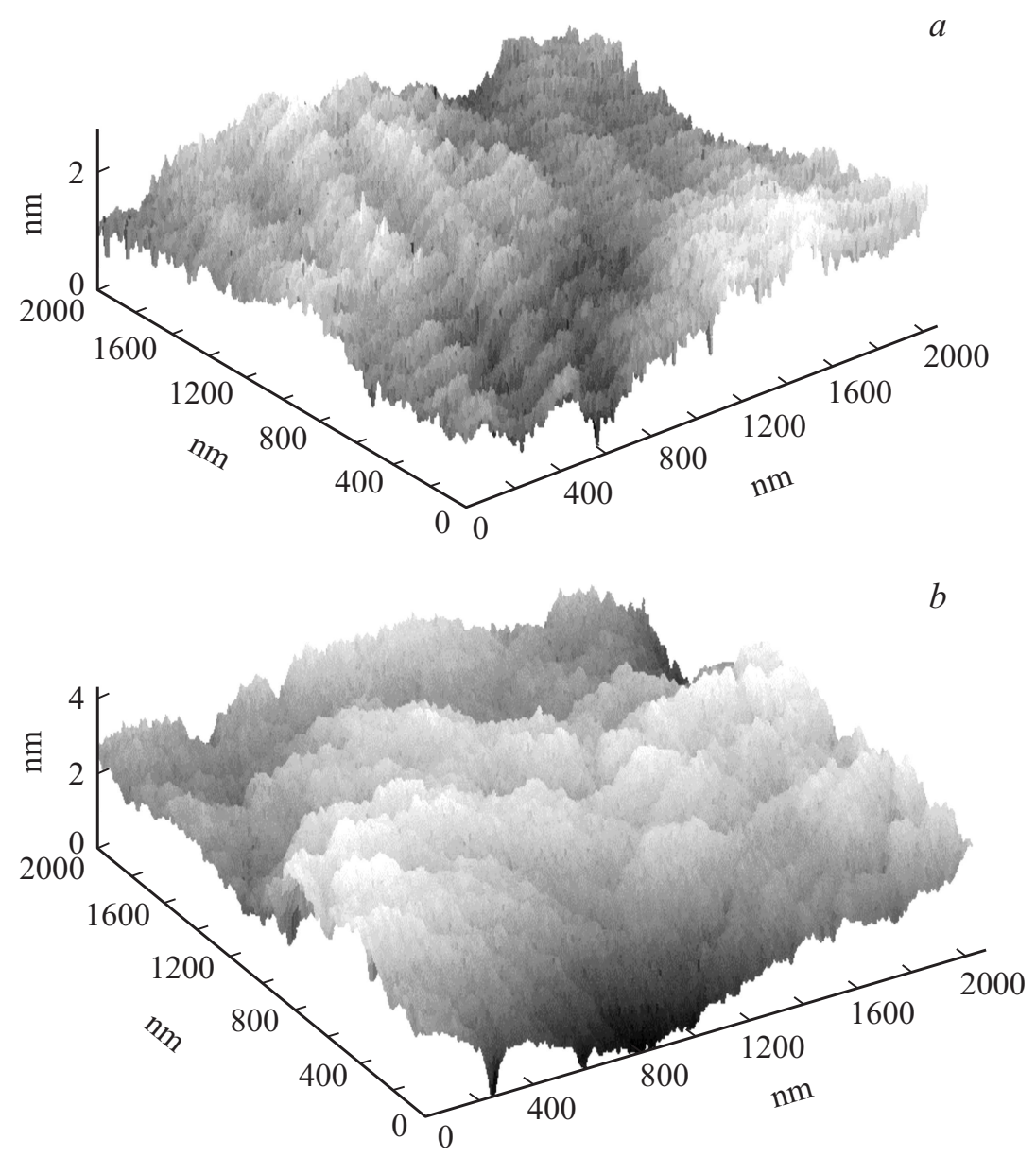

Рис. 1. Изображения в атомно-силовом микроскопе поверхностей $\mathrm{AlGaN} / \mathrm{GaN}-\mathrm{HEMT-структуры} \mathrm{с} \Delta_{p}=0.345$ до $(a)$ и после $(b)$ облучения протонами дозой $2 \cdot 10^{14} \mathrm{~cm}^{-2}$, а также НЕМТ-структуры после облучения дозой $1 \cdot 10^{14} \mathrm{~cm}^{-2}(c)$, с ухудшенной организацией наноматериала $\left(\Delta_{p}=0.350\right)$ до облучения.

Письма в ЖТФ, 2016, том 42, вып. 21 


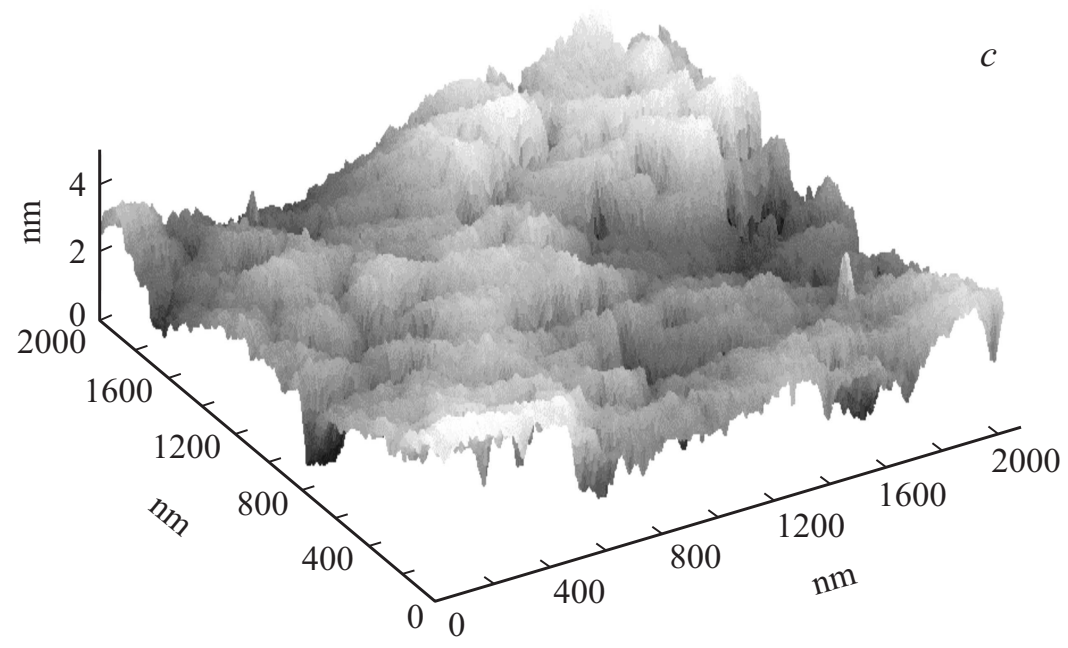

Рис. 1 (продолжение).

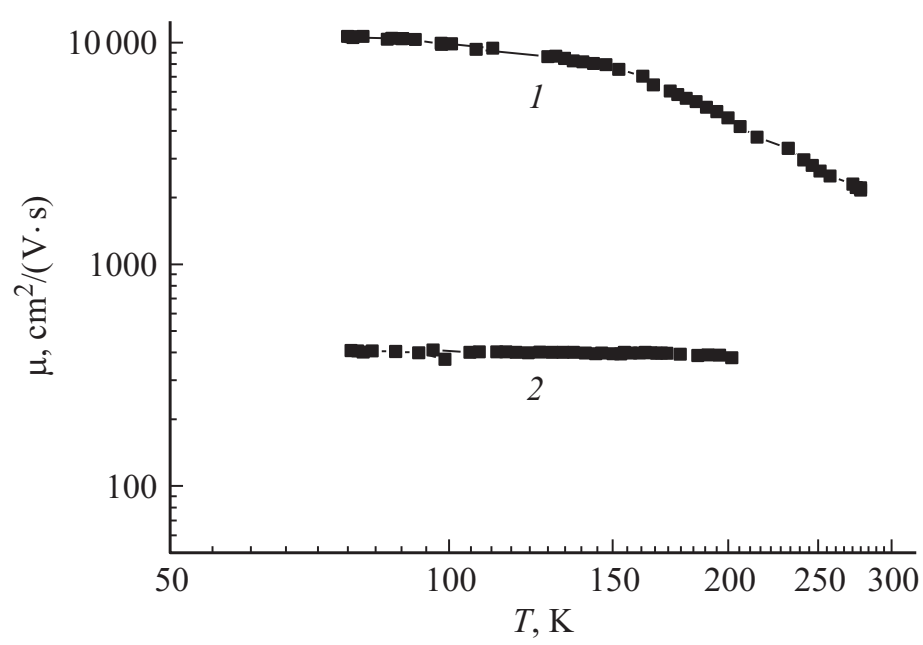

Рис. 2. Температурные зависимости подвижности в двумерном канале НЕМТструктуры с $\Delta_{p}=0.345: 1-$ до облучения протонами; $2-$ после дозы $2 \cdot 10^{14} \mathrm{~cm}^{-2}$

Письма в ЖТФ, 2016, том 42, вып. 21 
того, заметно растет доля нефункционирующих транзисторов (до 60\%) по сравнению с НЕМТ с меньшей разупорядоченностью (значения $\left.\Delta_{p}=0.345\right)$ до облучения. Полученные результаты позволяют предполагать, что интенсивное дефектообразование происходит, прежде всего, в локальных областях, например в скоплениях дилокаций, в $V$-дефектах, в дефектах упаковки, содержащих по всей глубине НЕМТ-структуры слабо связанные атомы как азота, так и галлия, и сопровождается изменением внутренней организации наноматериала, изменением механических напряжений на границах сросшихся доменов, а также проводящих свойств протяженных дефектов. Очевидно, что для обсуждения механизмов дефектообразования в системе протяженных дефектов и количественных оценок необходимы дополнительные исследования.

Таким образом, взаимодействие протонов с НЕМТ-структурами сопровождается не только генерацией точечных радиационных дефектов, но и локальным усилением разупорядоченности наноматериала (ростом значений параметра $\Delta_{p}$ ). Причем этот процесс развивается неоднородно по площади НЕМТ-структуры как на нанометровых, так и на микронных масштабах. При этом наблюдается корреляция между ухудшением свойств двумерного канала НЕМТ-структур и ростом значений параметра $\Delta_{p}$. Усиление локальной разупорядоченности наноматериала не только нарушает геометрию двумерного канала, но и может изменять распределение локальных механических напряжений, состав твердого раствора в локальных областях и приводить к неоднородному распределению тока под затвором, а также между стоком и истоком. Первые результаты, полученные в работе, показали значительное влияние локальной разупорядоченности наноматериала, как присутствующей в $\mathrm{AlGaN} / \mathrm{GaN}-\mathrm{HEMT-структурах} \mathrm{до,} \mathrm{так} \mathrm{и} \mathrm{усиливающейся} \mathrm{после} \mathrm{воз-}$ действия протонов на параметры транзисторов и их радиационную стойкость. Кроме того, полученные результаты проливают свет на имеющиеся в литературе данные разных авторов по расхождению пороговых значений радиационной стойкости и надежности транзисторов на основе $\mathrm{AlGaN} / \mathrm{GaN}-\mathrm{HEMT-структур.} \mathrm{Эти} \mathrm{результаты} \mathrm{показывают,} \mathrm{что}$ улучшение упорядоченности наноматериала и ее контроль в процессе производства транзисторов может стать одним из способов повышения радиационной стойкости и надежности НЕМТ-транзисторов.

Работа выполнена при финансовой поддержке государства в лице Министерства образования и науки РФ (соглашение № 14.574.21.0116, уникальный идентификатор проекта RFMEFI57414XO116).

Письма в ЖТФ, 2016, том 42, вып. 21 


\section{Список литературы}

[1] Коноплева Р.Ф., Остроумов В.Н. Взаимодействие заряженных частиц высоких энергий с германием и кремнием. М.: Атомиздат, 1975. С. 128.

[2] Оболенский С.В. // Микроэлектроника. 2004. № 2. С. 153-159.

[3] Shmidt N.M., Kolmakov A.G., Emtsev V.V., Lundin W.V. // Nanotechnology. 2001. V. 12. P. 471-474.

[4] Shabunina E., Averkiev N., Chernyakov A. et al. // Phys. Status Solidi. C. Curr. Top. Solid State Phys. 2013. V. 10. P. 335-337.

[5] Torkhov N.A., Novikov V.A. // Semiconductors. 2011. V. 45. P. 69-78.

[6] Встовский Г.В., Колмаков А.Г., Бунин И.Ж. Введение в мультифрактальную параметризацию структур материалов. М.: Центр, 2001. С. 116.

[7] Ankudinov A.V., Besyulkin A.I., Kolmakov A.G. et al. // Physica. B. 2003. V. 340 342. P. 462-466.

[8] Shalygin V.A.,Vorobjev L.E., Firsov D.A. et al. // J. Appl. Phys. 2011. V. 109. P. 073108.

[9] Громов Д., Чуков Г. Влияние радиации на гетероструктурные СВЧ приборы и интегральные схемы. Palamarium Academic Publishing, 2012. C. 91. 